\title{
Corneal ulceration following measles in Nigerian children
}

\author{
J. H. SANDFORD-SMITH, ${ }^{1}$ AND H. C. WHITTLE ${ }^{2}$ \\ From the ${ }^{1}$ Department of Ophthalmology, Ahmadu Bello University Hospital, Kaduna, and the \\ ${ }^{2}$ Department of Medicine, Ahmadu Bello University, Zaria, Nigeria
}

SUMMARY Acute corneal ulceration in malnourished children is the commonest cause of childhood blindness in Northern Nigeria and usually develops after measles. Other severe diseases in malnourished children rarely precipitate corneal ulceration. A survey in a school for blind children showed that $69 \%$ of the children were blind from corneal disease, and a survey of children with corneal scars showed that at least $42 \%$ were caused by ulceration after measles. The clinical appearance of the active ulcers was very varied. The serum retinol-binding protein and prealbumin levels in children with corneal ulcers following measles were below normal, but a group of malnourished children without eye complaints following measles were found to have even lower levels. Thus a specific deficiency of vitamin A does not appear to be the primary cause of these ulcers, though it may be a contributory one. A specific measles keratitis and secondary herpes simplex infections may be local factors contributing to this ulceration, and there is nearly always a background of protein calorie malnutrition. Racial factors may also be of some significance.

Severe corneal ulceration following measles is a common condition throughout sub-Saharan Africa. In all reported surveys of child blindness it is a very significant cause and often it is overwhelmingly the most important cause. Phillips (1961) in Zambia estimated that $81 \%$ of blindness was caused by measles, and Awdrey et al. (1967), also from Zambia, surveying an area where corneal blindness was common, found that $80 \%$ of the total blindness was due to corneal lesions and half of these were caused by measles. In Malawi Chirambo and Ben Ezra (1976) considered that measles was the cause of $44 \%$ of child blindness. Sauter (1976), in Kenya, found that $47 \%$ of child blindness was due to xerophthalmia and two-thirds of these cases were precipitated by measles. Quéré (1964), from Senegal, found corneal scarring after measles to be the commonest cause of childhood blindness. In a hospital survey from Southern Nigeria Olurin (1970) found that only $14 \%$ of child blindness. was caused by measles, and yet examination of the children in a blind school in Southern Nigeria showed that 33\% of the inmates and $79 \%$ of the new admissions were blind from measles (Animashaun, 1977).

It is usually considered that this acute corneal

Correspondence to Mr J. H. Sandford-Smith, FRCS, Department of Ophthalmology, Leicester Royal Infirmary, Welford Road, Leicester. ulceration is essentially a manifestation of vitamin A deficiency, so that a child with borderline vitamin A deficiency after contracting measles develops acute keratomalacia (Voorhoeve, 1966; Cobb and Awdrey, 1968; Oomen, 1971; Franken, 1974; Sauter, 1976).

In this paper we first assess the significance of measles as a cause of corneal ulceration and blindness in the local community and then compare the vitamin A status of children with corneal ulceration following measles to that of other children both well nourished and malnourished who contracted measles but did not develop any eye ulcers. Other factors that may contribute to the formation of these ulcers are then considered.

\section{Patients and methods}

All the children in Gindiri Blind School, the only school for visually handicapped children in Northern Nigeria, were examined to determine the cause of blindness. In some cases it was possible to obtain either from the children or the school records a history of any disease which precipitated the blindness. Seventy-four children were seen in 1975 and a further 30 in 1978. Because the pattern of pathology was not significantly different on the 2 occasions, the results of the 104 children seen in all are presented together.

All patients presenting at the Ahmadu Bello 
University Hospital, Kaduna, over a 3-month period February to April 1978 with a corneal scar from early childhood were examined and questioned to determine the cause of the original disease. Because most children attended with their mothers we could get a much more accurate description of the original illness. Also, this group included patients with disease in 1 eye only, who would not be seen in a blind school. Eighty-nine patients in all were seen in this group.

Seventy children were also seen at the Ahmadu Bello University Hospital, Kaduna, with acute, active corneal ulcers over a 12-month period in 1977-8. Particular note was made of any systemic disease which precipatated the ulceration and also the clinical appearance and morphology of the ulcers. The last 22 of these 70 children were investigated further to determine in particular their general nutritional and vitamin A status as follows: (a) Their weight for age was assessed according to the Harvard standard (Jelliffe, 1966), and tabulated as recommended by the World Health Organisation (1971). (b) Serum retinol-binding protein and prealbumin levels were estimated by the gel immunodiffusion method of Mancini using monospecific antisera (Behringwerke) and a standard human serum (Behringwerke) which contained known amounts of retinol-binding protein and prealbumin.

Their mean age was 22 months, range 9-72 months, and they presented on average at 13 days (range 5-30 days) after measles. For comparison retinol-binding protein and prealbumin levels were also estimated on the following age-matched children within 1 month of their having measles and without any evidence of eye ulceration: 12 well nourished children (more than $80 \%$ weight for age of Harvard standard), and 12 malnourished children. Seven of the children in this group were marasmic, and 3 had marasmic kwashiorkor and 2 kwashiorkor.

\section{Results}

The results of the blind school survey are shown in Table 1. When the children were questioned to assess the cause of the original corneal disease, about half attributed their blindness to measles. One case was due to an injury, two to smallpox, and the remainder were unable to give any description of their original illness.

The results of the hospital survey of patients with corneal scarring is shown in Table 2. The signifcance of measles is further shown in comparing the ocular damage produced by it to the damage produced from other causes. Of the eyes affected by measles 19 had useful vision, 21 no useful vision, and 18 total destruction of the eye. Of the eyes
Table 1 Causes of blindness of 104 children in Gindiri Blind School, Northern Nigeria

\begin{tabular}{lcc}
\hline Cause of blindness & Total no. & $\%$ of total \\
\hline Phthisis bulbi, staphyloma, or corneal & 72 & $69 \cdot 2$ \\
$\quad$ scarring & 12 & $11 \cdot 5$ \\
Retinal degeneration & 5 & 4.9 \\
Optic atrophy & 5 & 4.9 \\
Uveitis & 4 & 3.8 \\
Glaucoma & 3 & 2.9 \\
Cataract & 2 & 1.9 \\
Undertermined & 1 & 0.9 \\
Normal & 104 & 100 \\
\hline
\end{tabular}

Table 2 Probable original cause of corneal scar in 89 outpatients presenting with corneal scarring

\begin{tabular}{lrrrrrr}
\hline & \multicolumn{2}{l}{$\begin{array}{l}\text { Bilateral } \\
\text { scarring }\end{array}$} & \multicolumn{2}{l}{$\begin{array}{l}\text { Unilateral } \\
\text { scarring }\end{array}$} & \multicolumn{2}{c}{ Total } \\
\cline { 2 - 7 } Probable cause & No. & $\%$ & No. & $\%$ & No. & $\%$ \\
\hline Measles & 21 & 54 & 16 & 32 & 37 & 42 \\
Trauma & 1 & 3 & 10 & 20 & 11 & 12 \\
Smallpox & 3 & 8 & 2 & 4 & 5 & 6 \\
Trachoma & 4 & 10 & 1 & 2 & 5 & 6 \\
Herpes simplex & - & - & 6 & 12 & 6 & 7 \\
Ophthalmia neonatorum & - & - & 2 & 4 & 2 & 2 \\
Vernal eye disease & 1 & 3 & - & - & 1 & 1 \\
Phlyctenular conjunctivitis & - & - & 1 & 2 & 1 & 1 \\
Congenital & - & - & 1 & 2 & 1 & 1 \\
Unknown & 9 & 23 & 11 & 22 & 20 & 22 \\
\hline
\end{tabular}

Table 3 Precipitating disease in the 70 children with active corneal ulceration

\begin{tabular}{lcc}
\hline Disease & No. of patients & $\%$ of total \\
\hline Measles & 63 & 90 \\
Gastroenteritis & 3 & 4 \\
Acute malnutrition & 2 & 3 \\
No antecedent disease & 2 & 3 \\
\hline
\end{tabular}

affected by other inflammations (i.e., all those except the trauma and unknown groups) 22 had useful vision, 6 no useful vision, and 1 had total destruction of the eye.

The precipitating disease in the 70 children with active corneal ulceration is shown in Table 3. 


\section{CLINICAL APPEARANCE OF ULCERS}

The morphology of the active ulcers was very varied, often differed in the 2 eyes, and changed as the disease progressed. In only a few patients was it possible to observe the disease throughout its course, and in most cases severe ulceration had developed when the patient was first seen. (The changes recorded are those when first seen.) The ulcers were classified according to their appearance as follows:

Superficial punctate keratitis. This was seen in the early acute stage of measles. It was always bilateral and often associated with diminished tear production. Although this might progress directly to frank ulceration, there was sometimes a delay of a few weeks before the onset of ulceration.

Superficial ulcers. These were very irregular in distribution and varied in appearance from being very localised or dendritic, through more widespread involvement or 'geographical', to very extensive involvement or 'amoeboid'.

Deep stromal ulcers. These were mostly central or below the centre, but a few were very irregular in distribution. Seventeen out of 42 of these ulcers showed evidence of perforation.

Total corneal necrosis. This was obviously the most severe type of ulceration in which the entire corneal stroma had disappeared leaving the iris covered with a mixture of mucus, fibrin, and pus.

Exposure keratitis. In some cases the ulcer was localised to the lower cornea and had a clearly defined horizontal upper border, as is typical of exposure keratitis.

The incidence of the different types of ulcer and whether they were unilateral or bilateral is shown in Table 4. Several children had ulcers on other parts of the body. Sixteen had mouth ulcers, 1 of whom also had an ulcer of the thumb that she sucked; 1 had cancrum oris, 1 had an eyelid ulcer, and 1 had vulval ulcers.

Immunofluorescent staining or viral culture on eye scrapings from 34 of these children with active

Table 4 Clinical appearance in 70 children with active corneal ulceration

\begin{tabular}{lrrrrr}
\hline \multirow{2}{*}{ Type of ulcer } & \multicolumn{2}{l}{$\begin{array}{l}\text { Unilateral cases } \\
\text { (other eye normal) }\end{array}$} & \multicolumn{2}{l}{$\begin{array}{l}\text { Bilateral } \\
\text { cases }\end{array}$} \\
\cline { 2 - 6 } & No. & $\%$ & No. & $\%$ \\
\hline Superficial punctate keratitis & 0 & 0 & 8 & 20 \\
Epithelial ulceration & 9 & 31 & 9 & 22 \\
Stromal ulceration & 16 & 55 & 13 & 32 \\
Total corneal necrosis & 3 & 10 & 5 & 12 \\
Exposure keratitis & 1 & 3 & 6 & 15 \\
Total & 29 & & 41 & \\
\hline
\end{tabular}

Table 5 Nutritional status of the last 22 children with active corneal ulceration

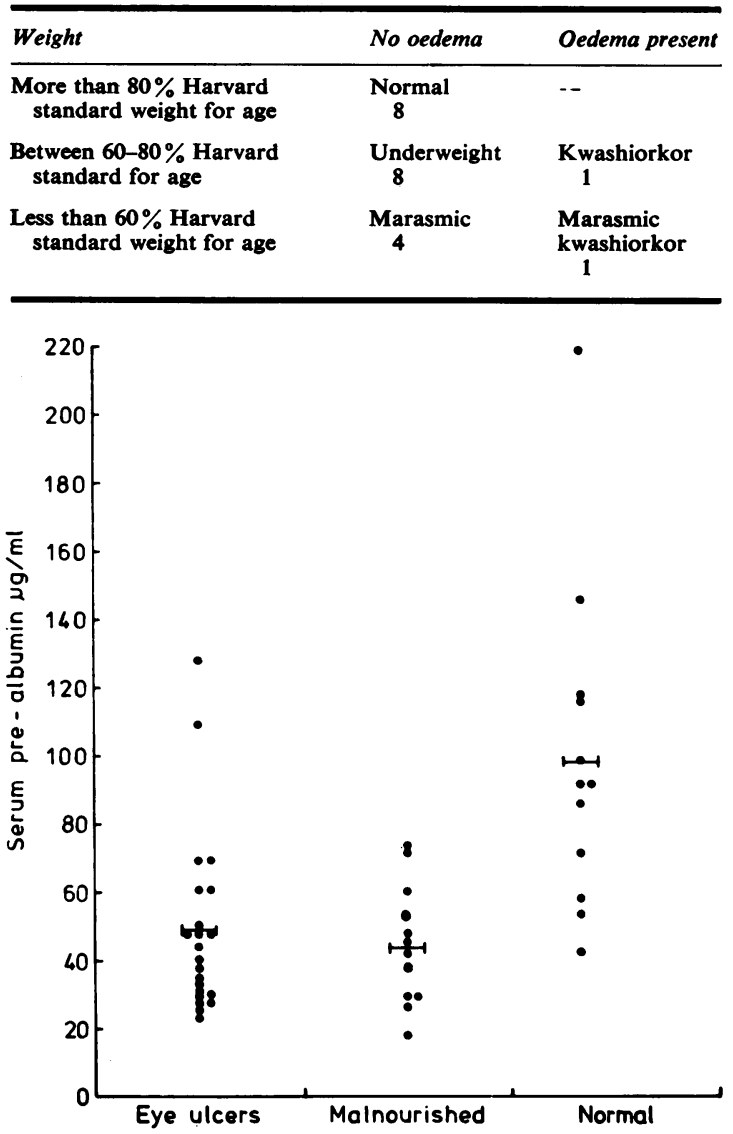

Fig. 1 Serum prealbumin levels in children with acute ulcers, malnourished children, and well nourished children. The mean for each group is also shown

corneal ulcers after measles detected herpes virus in 16 and measles virus in 4 (see Whittle et al. (1978) for full details. This was part of a different study on some of the same group of patients).

\section{NUTRITIONAL STUDIES}

The weight for age of the 22 children in whom this was measured is shown in Table 5.

The serum prealbumin levels in these children and in the 12 well nourished and 12 malnourished children after measles but with normal eyes are shown in Fig. 1. There was no significant difference between serum prealbumin levels in those with eye ulcers and the malnourished children without eye ulcers. They averaged $48.3 \pm$ SD $27.5 \mu \mathrm{g} / \mathrm{ml}$ and $45 \cdot 1 \pm \mathrm{SD} 14 \cdot 5 \mu \mathrm{g} / \mathrm{ml}$ respectively.

The serum retinol-binding protein levels for 


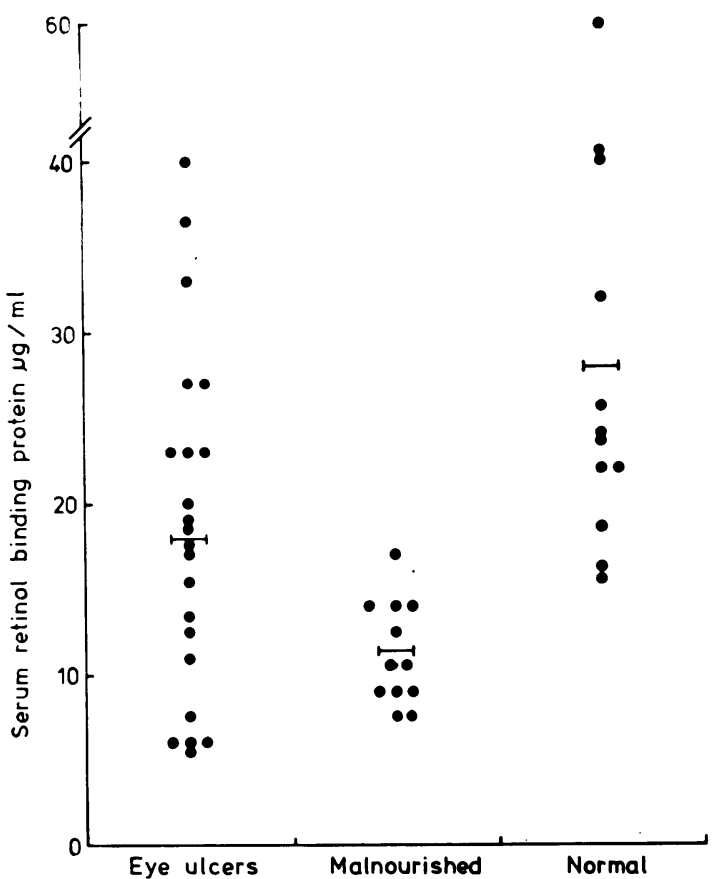

Fig. 2 Serum retinol-binding protein levels in children with acute ulcers, malnourished children, and well nourished children

these same children is shown in Fig. 2. There was a significant difference $(\mathrm{P}<0.05)$ between serum retinol-binding protein levels in those with eye ulcers and the malnourished children without eye ulcers. They averaged $18.5 \pm \mathrm{SD} 10.0 \mu \mathrm{g} / \mathrm{ml}$ and $11.3 \pm \mathrm{SD} 2.9 \mu \mathrm{g} / \mathrm{ml}$ respectively. Fourteen out of the 22 children with eye ulcers had retinol-binding protein levels in the normal range. These tended to be the better nourished children, a fact supported by the positive and significant correlation between retinol-binding protein and prealbumin levels in these children $(r=+0.48, P<0.05)$.

\section{Discussion}

The studies we have carried out on blind school children and on outpatients with corneal scars from early childhood confirm the results of other workers in different parts of sub-Saharan Africa that corneal ulceration is the commonest cause of child blindness and measles the commonest cause of corneal ulceration. However, the studies on children with active ulcers do not support the theory that this condition is primarily a manifestation of vitamin A deficiency, though it may often be a factor of some significance.

More than half the children with active ulcers had retinol-binding protein levels within the range of normal, and the mean retinol-binding protein level was higher in the children with active ulcers than in a group of malnourished children without ulcers.

The lesions are often unilateral, 29 out of 70 cases in this series $(41 \%)$. In several instances one eye was grossly affected and the other eye completely normal, with no conjunctival xerosis or tear film abnormalities. This would obviously be impossible in true vitamin A deficiency.

Vitamin A deficiency is often precipitated by acute infection, but in this study severe and debilitating childhood disease other than measles only very rarely predisposes to corneal ulceration. Gastroenteritis in particular, which attacks children in the vulnerable postweaning period, is often associated with extreme malnutrition, and has a very high mortality rate, was the precipitating cause of ulceration in only $3(4 \%)$ of these cases.

In addition the early stages of xerophthalmia are very rarely seen in this area even in malnourished children attending nutrition clinics, and the ulcers once present do not seem to respond to vitamin A treatment. The disease appears to be common in Southern Nigeria, where red palm oil (one of the best known sources of vitamin A) is a basic food stuff. In a recent survery of children with measles from Lagos, in Southern Nigeria, almost $1 \%$ were blinded by corneal ulceration (Animashaun, 1977). Although red palm oil is not widely used in this part of Nigeria, carrots, tomatoes, and mangoes are all available at different times of the year, and recall dietary investigation of children with measles and malnutrition would indicate that dietary vitamin $\mathbf{A}$ is not grossly deficient.

The relationship between vitamin A deficiency and protein calorie malnutrition is complex. Vitamin $\mathbf{A}$ is stored in the liver and distributed to the tissues bound to retinol-binding protein. This will fall in protein malnutrition, thus causing a tissue deficiency of vitamin A even in the presence of potentially adequate vitamin $A$ in the diet. This has been demonstrated by giving malnourished children diets containing no significant vitamin A, and the serum retinol and retinol-binding protein both returned to normal (Igenbleek et al., 1975). Moreover, acute measles can produce a proteinlosing enteropathy, thus lowering even further the levels of retinol-binding and serum protein (Dossetor and Whittle, 1975).

Protein calorie malnutrition is obviously a significant background factor in the pathogenesis of these ulcers. Many of the children with acute ulcers were malnourished as shown by their weight for age and serum prealbumin levels, and there was a tendency for more severe ulceration to be seen in 
the more malnourished children. Thus all the 5 children with bilateral total corneal necrosis were clinically malnourished and 3 of them were marasmic. By contrast there were 10 children with active ulcers who were considered to be well cared for and well fed, and who all had a weight for age over $80 \%$, and 8 of these 10 had only unilateral ulceration.

Measles itself appears to be a significant factor, as shown by the marked superficial punctate keratoconjunctivitis and diminished tear production in the early stages of the disease. This was first observed by Trantas (1907) and has recently been noted in detail in malnourished children in Kenya (Dekkers, 1978).

Measles and malnutrition are known to produce depression of the cellular immunity, thus predisposing to secondary herpes infections. The morphology of many of the ulcers was typical of herpes in an immunosuppressed patient, and this has been confirmed by culture and immunofluorescence studies (Whittle et al., 1978). It is possible also that measles has a local effect in specifically triggering herpes infections of the eye and mouth. By contrast, in a survey of 500 cases of meningococcal meningitis under the age of $5,15 \%$ developed herpetic vesicles of the face but none were in the eye, and they all recovered quickly (Whittle, unpublished).

Many of these children lie dehydrated and exhausted in a hot atmosphere, and lid closure becomes defective, leading to desiccation and ulceration of the exposed lower cornea.

Paediatricians who have worked both in Asia and in Africa often comment on the increased severity of measles in Africa, which may be racial. In Asian communities where xerophthalmia is rife measles does not seem to have such significance in causing corneal ulceration. It is interesting that one of the few reports describing postmeasles ulceration from outside Africa is from Haiti, a Negro community (Girard et al., 1969).

For local treatment of the individual case we would emphasise prevention of exposure changes to the cornea in the acute stage of the illness by local care to the eyes, the application of oily antibiotic drops or ointment, and if necessary careful padding. For ulceration developing later we would stress the use of antiviral agents as well as local and subconjunctival antibiotic agents, and debridement may also be helpful.

Nearly always the general condition of the child requires urgent treatment also, which is obviously beyond the scope of this paper. Adequate parenteral or oral vitamin A must always be given.

In conclusion, postmeasles corneal ulcers are obviously caused by a variety of interacting factors, but it is important to try to identify which are the most significant of these in order to plan an effective programme of prevention of blindness in childhood. It would seem to us that measles vaccination is likely to be more effective than efforts to improve the general nutritional or vitamin A status of the community.

We thank Mrs Werblinska for her excellent technical help.

Part of the study was supported by grants from the Medical Research Council (UK), and the Royal Commonwealth Society of the Blind.

\section{References}

Animashaun, A. (1977). Measles and blindness in Nigerıan children. Nigerian Journal of Paediatrics, 4, 10.

Awdry, P. N., Cobb, B., and Adams, P. C. G. (1967). Blindness in the Luapula valley. Central African Journal of Medicine, 13, 197-201.

Chirambo, M. C., and Ben Ezra, D. (1976). Causes of blindness among students in blind school institutions in a developing country. British Journal of Ophthalmology, 60, 665-668.

Cobb, B., and Awdrey, P. N. (1968). Xerophthalmia. Transactions of the Ophthalmological Societies of the United Kingdom, 88, 579-585.

Dekkers, N. (1978). Paper presented at First Annual General Assembly of International Agency for Prevention of Blindness, Oxford. To be published.

Dossetor, J., and Whittle, H. C. (1975). Protein losing enteropathy and malabsorption in acute measles enteritis. British Medical Journal, 2, 592.

Franken, S. (1974). Measles and xerophthalmia in East Africa. Tropical and Geographical Medicine, 26, 39-44.

Girard, F., Howard, O. R., and Boniuk, V. (1969). Corneal ulcers in rubella. American Journal of Ophthalmology, 68, 996-1000.

Igenbleek, Y., van der Schrieck, H. G., Denayer, P., and de Visccher, M. (1975). The role of retinol binding protein in protein-calorie malnutrition. Metabolism, 24, 633-639.

Jelliffe, D. B. (1966). The Assessment of the Nutritional Status of the Community. World Health Organisation, monograph series No. 53. Geneva.

Olurin, O. (1970). Etiology of Blindness in Nigerian children. American Journal of Ophthalmology, 70, 533-540.

Oomen, J. M. V. (1971). Xerophthalmia in Nigeria. Tropical and Geographical Medicine, 23, 246-249.

Phillips, C. M. (1961). Blindness in Africans in Northern Rhodesia. Central African Journal of Medicine, 7, 153-158.

Quéré, M. A. (1964). Les complications oculaires de la rougeole, cause majeur du décité chez l'enfant en pays tropicales. Ophthalmologica, 148, 107-120.

Sauter, J. J. M. (1976). Measles and xerophthalmia in Kenya. Doctoral thesis, University of Gröningen.

Trantas. (1907). Keratite examthématique pendant la rougeole et d'autres maladies examthématiques. Bulletin de la Société Française d'Ophthalmologie, 24, 592-612.

Voorhoeve, H. W. A. (1966). Xerophthalmia and kwashiorkor in 6 children in Ibadan. Tropical and Geographical Medicine, 18, 15-19.

Whittle, H. C., Sandford-Smith, J. H., Kogbe, O., and Duggan, M. (1978). Severe ulcerative herpes of mouth and and eye after measles. Transactions of the Royal Society of Tropical Medicine and Hygiene (in press).

World Health Organisation and Food and Agriculture Organisation (1971). 8th Report Joint FAO/WHO Expert Committee on Nutrition. Technical Report Series No. 447. Geneva. 